\title{
La inmigración italiana en \\ Santa Fe: español e italiano en contacto. Motivaciones, metodologías y primeros resultados de un proyecto internacional
}

\author{
John Hajek \\ University of Melbourne \\ Susana Dorato • \\ Universidad Nacional del Litoral - \\ Universidad Autónoma de Entre Ríos
}

\section{Resumen}

La inmigración italiana en Santa Fe y alrededores presenta un fenómeno de contacto e hibridación lingüística entre el español local y el italiano y los dialectos de los inmigrantes. Este campo de estudio hasta la fecha se presenta como una notable área de vacancia. El artículo constituye un avance sobre las motivaciones, metodologías y resultados de una primera etapa de trabajo en el marco de un proyecto internacional entre estudiosos de la Universidad del Litoral y la Universidad de Melbourne, Australia, tendiente a describir y analizar las características y las consecuencias del contacto.

\section{Palabras clave}

· Inmigración italiana · contacto lingüístico · italiano y español · Argentina

\footnotetext{
- Luego de graduarse en Estudios Italianos y Franceses en la Universidad de Melbourne ha completado sus estudios universitarios en Italia (Florencia y Padua) y en Inglaterra (Oxford). Actualmente es profesor ordinario de Italianística en la Universidad de Melbourne donde también es Director del RUMACCC (Research Unit for Multilingualism and Cross-cultural Communication).

- Egresada de la carrera de Profesorado en Italiano en 2001 en la Universidad Autónoma de Entre Ríos donde desde 2004 participa de las cátedras Italiano / y II, Literatura Italiana I y II, Fonética y Fonología Italiana II. Entre 2011 y 2013 ha participado de la cátedra de Historia de la Lengua Italiana. Desde 2015 trabaja en la Universidad Nacional del Litoral en la Cátedra de Italiano I. Integró el equipo del Laboratorio de Historia Oral (CEC-UNL) durante el período marzo 2018-mayo de 2019.
} 


\begin{abstract}
Italian immigration in and around Santa Fe presents a phenomenon of contact and linguistic hybridization between the local Spanish and the Italian and the Italian dialects of immigrants — a field of study that to date remains open for study. This contribution outlines the motivations, methodologies and results of the first stage of work within the framework of an international project between scholars from the Universidad Nacional del Litoral and the University of Melbourne, Australia, aimed at describing and analyzing the characteristics and consequences of contact.
\end{abstract}

\title{
Key words
}

- Italian immigration · linguistic contact · Italian and Spanish . Argentina

En el mes de julio de 2018, John Hajek, Profesor de Italianística y Director del RUMACCC (Research Unit for Multilingualism and Cross-cultural Communication) de la University of Melbourne, Australia, visitó la ciudad de Santa Fe donde concretó una serie de experiencias con un grupo de integrantes y colaboradores del Proyecto CAID - UNL 2016-2020 Tradiciones selectivas: trazo(a)s presentes y emergentes de la migración italiana y francófona en la ciudad de Santa Fe y del Programa de Estudios sobre Migraciones «Lina y Charles Beck-Bernard», ambos con sede en el Centro de Estudios Comparados de la Facultad de Humanidades y Ciencias de la Universidad Nacional del Litoral, dirigidos por la Prof. Adriana Crolla.

La estadía del Prof. Hajek constituyó una feliz circunstancia para concluir un acuerdo de colaboración mutua y en este artículo se presentan las motivaciones iniciales, las metodologías de trabajo y los primeros resultados del proyecto de colaboración internacional que comenzó a realizarse desde entonces, entre el grupo de investigadores altamente formados en el estudio y detección de casos de lenguas en contacto, dirigido por John Hajek en la sede australiana y el grupo coordinado por la Prof. Susana Dorato, en el seno de las acciones proyectadas en la sede santafesina.

Desde un punto de vista teórico, la categoría de «teorías ambulantes» de Edward Said (2004: 303-332) resulta operativa al sostener que la vida intelectual se alimenta y mantiene gracias a la circulación, apropiación, comercio y préstamos de ideas y teorías, lo que constituye una afortunada condición instrumental para la colaboración internacional. Por otra parte, resulta pertinente citar la diferencia que establece Raymond Williams ([1980] 2002), entre la tradición que considera al pasado como un segmento histórico inerte, y la «tradición selectiva» que piensa el pasado como configurativo. La tradición, al ser «selectiva», opina Williams, pue- 
de ser entendida como un aspecto propio de la organización social y cultural del presente, que responde a intereses de dominación tanto de la hegemonía como de las contrahegemonías que operan en resquicios vulnerables y alternativos. A la luz de lo antes expresado, se reivindica a la tradición como un proceso activo que se determina desde el ahora para leer el ayer y permite, a partir de plurales maniobras de selección, pensar la cultura como producción social de sentido obligándonos a meditar y a estudiar en modo excavatorio y autorreflexivo, los textos y discursos de la identidad desde el relato de su propia construcción (y exclusiones). Buscar en tanto investigadores y académicos, los trazos y trazas en interacción operante con el presente y con el afuera, en la dinámica de la multidiversidad que las/ nos cohabita (Crolla, 2015: s/d).

De allí se parte para abordar, en modo corporativo entre sedes alejadas en el espacio pero no en los intereses, un área de vacancia en los estudios académicos locales en relación con la lengua santafesina y el componente extranjero que la habita. Se hipotetiza que el habla local atesora una sonoridad lingüística que no refiere exclusivamente al pasado colonial español que la doxa local siempre ha destacado y estudiado, sino a un componente sonoro variado construido por las lenguas migrantes europeas, judaica, turca, eslavas y también aborígenes. Patrimonio sonoro que la hegemonía de la crítica de prosapia espańolizante fundacional ha soslayado, o lo que es peor, negado.

En indagaciones previas sobre la ciudad de Santa Fe se detectó una ausencia total de estudios de impronta lingüística y un escaso desarrollo en abordajes sociológicos, desde esta perspectiva, que hagan visible su gravitación en los ámbitos económicos, políticos y socio-culturales y sobre la operatividad todavía vigente de las reticulaciones instauradas por las redes migrantes.

Es así que para el caso de los estudios lingüísticos, se hacía imperioso diseñar enfoques metodológicos más pertinentes a fin de poder abordar el estudio del universo sonoro seleccionado, partiendo de la certeza de estar inaugurando un ámbito de indagaciones todavía inexplorado.

Ya desde la primera fase del proyecto piloto la experiencia se presenta como altamente positiva, en tanto los investigadores de la sede australiana aportan su conocimiento y experiencia en el análisis de lenguas en contacto. Esto redunda en el desarrollo de saberes y prácticas que los integrantes del equipo santafesino podrán alcanzar para analizar interferencias lingüísticas todavía detectables en migrantes y descendientes de origen italiano residentes en la zona y cuyas entrevistas han empezado a ser alojadas en un repositorio virtual creado a tal fin. Esto permitirá, al mismo tiempo, cubrir un espacio de vacancia en sede australiana sobre la realidad de la inmigración italiana en esta parte de la Argentina y en la UNL, por otra parte, la generación de metodologías ad hoc para estudiar el fenómeno y su formalización en estudios académicos, hasta el momento limitados en este ámbito, a pesar de la alta cantidad de migrantes italianos radicados en la zona.

Es, por lo tanto, la primera etapa de un proyecto de más amplia envergadura que se espera potenciar durante los próximos años para estudiar colaborativamente y en modo progresivo la situación de las lenguas en contacto, español - italiano I dialectos italianos en la zona seleccionada, lográndose también una mayor visibilidad a partir de la difusión de los resultados que garantiza la sede australiana, hacia contextos alejados de la Argentina. 


\section{Argentina y Australia: ¿dos inmigraciones italianas diferentes?}

¿Por qué la inmigración italiana en Argentina debiera interesar a un investigador australiano? Los dos contextos nacionales de inmigración son parcialmente similares pero en muchos aspectos claramente diferentes, hecho que suscita el interés australiano. También Australia fue una meta importante para los italianos pero en período y contextos muy diferentes. El importante ingreso de éstos en Australia se inicia a partir de 1951 y en mayor volumen luego de un acuerdo firmado por el gobierno australiano con su homónimo italiano en 1950. Si bien siempre hubo presencia de este origen, la notable expansión de la comunidad en Australia producida a partir de los '50 jamás alcanzó los extraordinarios niveles registrados en Argentina entre fines del siglo XIX y comienzos del XX.

Por otra parte, la inmigración italiana en Australia está mayormente concentrada en centros urbanos —en particular en Melbourne, Adelaida y Sydney—, ciudades que se encuentran a lo largo de la costa australiana, y generalmente con poca presencia italiana en las zonas internas del país. Por otra parte, el contexto cultural y lingüístico es completamente diferente: los italianos debieron integrarse a un país fuertemente anglosajón y anglófono. Dadas las diferencias lingüísticas entre el inglés (lengua germánica) y el italiano y sus dialectos (lenguas romances), el contacto entre esas lenguas en Australia presenta una tipología muy diferente a la argentina a partir del contacto entre lenguas romances, donde las semejanzas intrínsecas pueden confundir fácilmente las líneas de demarcación entre las mismas. Estas semejanzas, a su vez, pueden mostrar efectos de contacto más sutiles y más interesantes de observar.

\section{La lengua de los gringos}

Como es notorio, la República Argentina ha sido durante más de un siglo el punto de llegada de millones de italianos emigrados por diferentes motivos (económicos, políticos, sociales, etc.), que abandonaron su país en busca de una vida nueva con mayor o menor fortuna.

En 1901, Luigi Barzini, periodista del Corriere della Sera visitó la República Argentina para observar in situ las condiciones de vida de los emigrados italianos, escribiendo una serie de artículos en los cuales describía el país desde diferentes puntos de vista. Estos textos fueron recogidos y publicados en el libro L'Argentina vista com' $e$, cuyo prefacio comienza en este modo: «Desde Italia emigraron el año pasado medio millón de habitantes. La emigración nuestra, surgida, continuada y aumentada hasta estas aterradoras proporciones en medio de una marcada indiferencia, vino imprevistamente a imponerse sobre nuestra preocupación como uno de los problemas más graves, más complejos y más urgentes»" ${ }^{1}$ Barzini 1902:3).

«Aterradoras proporciones» que escandalizaban a Barzini con el dato inicial de quinientos mil emigrados en un año (unos 1360 por día), mayormente provenientes de pequeños pueblos de montańa o de zonas rurales, que intentaban escapar de 
las condiciones de miseria y atraso en las cuales vivía gran parte de la población italiana ante "la indiferencia» de las clases dirigentes, las cuales despertaron demasiado tardíamente.

Aun cuando a menudo se tiende a pensar en la inmigración italiana de Buenos Aires, muchos de quienes llegaron a la Argentina se asentaron en la zona central del país, que luego pasó a llamarse «La Pampa Gringa» debido a la explosión demográfica ocurrida en pocos años. Ésta se debió a una política de apertura hacia la inmigración llevada a cabo desde 1852 por el gobierno de Urquiza, primer presidente de la Confederación Argentina, quien estaba interesado por potenciar gran parte del territorio nacional aún improductivo y ocupado por diferentes tribus autóctonas que en aquellos tiempos se presentaban como un grave problema para el desarrollo de la nación.

Leonardo Paso, analizando las premisas de la Constitución Nacional Argentina y las ideas de su redactor Juan Bautista Alberdi, opina: «Por eso sostuvo que la Constitución Argentina era la constitución de un desierto y la más conveniente [propiciatoria de una inmigración masiva], ya que tendía a hacerlo desaparecer» (Paso 1985: 73).

Y así, con la idea de hacer desaparecer «el desierto», en 1858 nace Esperanza, primera colonia agrícola fundada por Aarón Castellanos y poblada por inmigrantes provenientes de Alemania, Suiza, Francia y más tarde del norte de Italia.

$\mathrm{Si}$ bien el inicio no fue fácil, las colonias se presentaron como una gran oportunidad inmobiliaria para los empresarios argentinos y europeos y en menos de veinticinco años éstas se multiplicarían y los arribos serían cada vez más frecuentes.

En las provincias de Santa Fe y Córdoba se asentaron los «colonos», los "gringos», como son llamados afectuosamente hasta hoy. Gran parte de ellos era de origen piamontés; fundaron una cadena de colonias en las cuales se habló y aun hoy se habla el dialecto: "por largas décadas todavía las palabras "agricultor" y "colono" serán prácticamente sinónimos en el mundo rural pampeano» (Djenderedjan 2007: 4).

La variación lingüística siempre ha sido un fenómeno característico de la península itálica. En la época de la unificación italiana en 1861, se afirma que pocos sabían hablar bien el italiano; para la mayoría de ellos la primera y típicamente la única lengua era el dialecto o la lengua regional. Por tal motivo, el mosaico dialectal fue una realidad lingüística que caracterizó el habla de los italianos y determinó el uso lingüístico de los inmigrantes.

También Barzini reflexiona sobre esta realidad en el artículo del 11 de agosto de 1902:

En la lengua está el secreto de la unión, el baluarte de la nacionalidad. Y bien, ¿̨cuántos italianos en Italia hablan italiano?

Los cultos, todos. Pero nosotros sabemos que desgraciadamente éstos no forman la mayoría de la masa emigrante. Los demás hablan lígure, siciliano, romañól, lombardo, napolitano, piamontés pero no italiano. Al norte nuestra lengua no supera Pistoia y ni va más al sur de Roma. Un pobre trabajador de Abruzzo se encontrará frente a un inmigrante lígure como frente a un extranjero ${ }^{2}$. (Barzini 1902: 176)

Esta dinámica lingüística continuó así por décadas en la Italia unificada. Solo en los años ‘ 60 del siglo XX se traspasó del uso del dialecto al italiano, lengua standard por decirlo de algún modo, la lengua de uso. Este traspaso se debe a los esfuerzos de los gobiernos italianos durante un siglo en contra de los dialectos y en favor del 
italiano, con la idea de crear finalmente una nación italiana de ciudadanos unidos a través de una lengua nacional compartida por todos.

La inmigración italiana en Argentina refleja la situación tradicional en Italia: los recién llegados tendían a dividirse por origen regional y continuaban usando sus dialectos al menos en los contextos informales y de cada día. También debían adaptarse al nuevo contexto argentino: intentaban aprender la lengua local lo mejor que podían, pero cuando la situación económica se los permitía fundaban escuelas en las que los docentes debían desarrollar las clases en la lengua de los migrantes, posibilitando así que ésta funcionara como lengua franca de la vida, la cultura y el comercio entre las colonias y los mercados de las ciudades vecinas. De hecho, en las colonias italianas de la Provincia de Santa Fe y Córdoba aún hoy los más ancianos continúan hablando su dialecto de origen. El piamontés, por ejemplo, es fuertemente sentido como la lengua de los «gringos». Se usaba pues, una especie de pidgin que la estudiosa en inmigración Adriana Crolla denomina "pasticcio»:

A diferencia del lunfardo, jerga porteńa extraordinariamente rica en italianismos, nacida de un consenso colectivo sobre sus significados, la lengua del inmigrante fue condicionada por la arbitrariedad del hablante quien, de las diferentes formalizaciones a disposición —dialectos, italiano y de la corrupción que provoca el "pasticcio» con el español—, elegía una con la que alcanzaba la comprensibilidad pero no el consenso. Un ejemplo de la enorme variedad a disposición puede ser: trabacar(e), lavorar(e); laburar(e); faticar(e); fatigar; trabajar. El italiano travagliare no constituyó nunca una opción en el habla inmigrante por pertenecer a la norma culta italiana y no existir, en consecuencia, en el repertorio de comunidades poco alfabetizadas. Tomamos del italiano el término "pasticcio» (lat. pasticiu(m) de păsta "pasta»): «mezcla compuesta de varios componentes, en sentido culinario». Figuradamente: «trabajo, discurso o escrito confuso o desordenado, tanto en el significado como en la forma». También, composición (teatral o musical) escrita en colaboración por varios compositores. En nuestras indagaciones nos resulta operativo utilizar este término para diferenciarlo del pastiche y del cocoliche, pues consideramos que la suma de las acepciones que da el diccionario para "pasticcio» habilita al uso del término para referirnos al fenómeno de hibridación lingüística operado en el habla de los inmigrantes y la contaminación que se produjo entre sus dialectos o italiano de origen con el español rioplatense. (Crolla, 2015: 21)

María Luisa Ferraris recupera a su vez esta categoría en su libro El malón y otros relatos:

La lengua «creada» por el inmigrante en el proceso de aculturación y de inserción lingüística cuya consecuencia es un pidgin o «pasticcio» como un fenómeno de hibridación lingüística realizado en el habla de los inmigrantes y la contaminación que se produjo entre sus dialectos o italiano de origen y el español rioplatense $e^{3}$. (Ferraris 2015:82)

Pero la vida en el campo era difícil y la enorme masa inmigrante encontraba problemas para insertarse en la nueva realidad. No todos permanecían en las zonas rurales, creando graves inconvenientes a nivel urbano. Muchas veces se alojaban familias enteras en una sola habitación de un "conventillo», encontrando puestos de trabajo con los cuales apenas llegaban a satisfacer sus necesidades básicas. De todos modos, con grandes esfuerzos los inmigrantes italianos pudieron sobrevivir en la nueva tierra, crearse una nueva existencia y producir riquezas llegando a ser hoy en día verdaderos pilares a nivel económico y social de Argentina. 
La tradición migratoria argentina esbozada en esta sede brevemente ha llamado la atención de muchos investigadores y estudiosos con particular impronta desde el punto de vista histórico. Solo en las últimas décadas del siglo XX algunas investigaciones se interesaron hacia el estudio de la lengua. El siempre recordado Giovanni Meo Zilio, con sus estudios sobre la realidad lingüística rioplatense, con la elaboración de glosarios sobre diferentes temáticas: desde la gastronomía hasta los apellidos, desde los gestos hasta las características fonológicas (v. Di Giorgio, 2006, Cancellier, 2015, 2011, Meo Zilio, 1989, 1993 y 1995 para una bibliografía completa $)^{4}$. Estudios de gran valor obviamente, pero concentrados solamente sobre las ciudades de Montevideo y Buenos Aires, el Lunfardo y el célebre Cocoliche (vgr. Angela Di Tullio, 2010), variedades caídas en desuso o relegadas simplemente a nivel de lengua literaria en el presente. Encontramos en cambio, pocas referencias a lo sucedido en otras regiones argentinas.

Un espacio de importante producción sobre la presencia de los italianos en distintas zonas de Córdoba es el concebido en el Centro de Italianística de la Escuela (luego Facultad de Lenguas) de la Universidad Nacional de Córdoba, publicados en su mayor parte en los Cuadernos CELI, bajo la dirección de la Dra. Trinidad Blanco de García.

Se encuentran disponibles también los resultados de indagaciones presentados por diferentes especialistas del país en los encuentros anuales de la Asociación de Docentes e Investigadores de Lengua y Literatura Italiana (ADILLI), publicados en las sucesivas actas.

En los últimos años, dos fuentes bibliográficas incrementaron estos desarrollos y han enriquecido el conjunto de materiales de base para la investigación. Se trata de: (a) la investigación llevada adelante por la Prof. Fulvia Lisi y su grupo perteneciente a la Universidad de Salta, en la cual se analizó la interacción entre el español y el italiano hablado en la ciudad de Salta por los inmigrantes y sus descendientes (Lisi, 2004) y (b) el estudio desarrollado por el investigador torinés Marco Giolitto, como tesis doctoral defendida en Suiza, y posteriormente traducida y publicada en español en Argentina (Giolitto, 2016), basada en una exhaustiva investigación que realizara sobre la inmigración piamontesa en colonias de la «Pampa Gringa».

Una tercera fuente que también sirve de base y referencia es el archivo documental y bibliográfico recogido durante un cuarto de siglo por el CEC - UNL y en parte integrado virtualmente al Portal Virtual de la Memoria Gringa, accesible en el link: http://www.fhuc.unl.edu.ar/portalgringo/crear/gringa/index_e.html.

El mismo constituye un espacio virtual que aglutina la mayor parte de las investigaciones sobre la lengua y la literatura de los migrantes de diferentes orígenes y de sus descendientes en la Región Centro de la República Argentina, y donde se radican las acciones del grupo de investigadores al cual pertenece la coautora argentina de este trabajo.

Nacido en 2006 como expresión de los nuevos tiempos, el Portal, creado y dirigido por la Prof. Crolla, es el órgano de comunicación del Centro de Estudios Comparados (CEC) y pretende constituirse como un ágora para la memoria y para todas la manifestaciones culturales referidas a las migraciones italófonas y francófonas en la Pampa Gringa argentina. Forman parte de esta propuesta: El Programa de Migraciones Lina y Charles Beck, el Museo Virtual Altrocché, el mapa de las colonias fundadas por los inmigrantes en la Provincia de Santa Fe, el archivo de tesis relativas a las migraciones, un catálogo de producciones referidas a la problemática publicados en distintas localidades a fin de configurar un vitraux lo más completo y exhaustivo 
posible, así como la construcción de archivos para la memoria de las letras, las artes figurativas, la historia y distintas aristas de la cultura de los procesos migrantes en la zona. También se publican periódicamente noticias relativas a las actividades y acciones del equipo de investigadores y del Centro de Estudios Comparados.

\section{Razones para un Laboratorio de Historia Oral}

En una zona de alta recepción migratoria, cuyo primeros grupos comenzaron a llegar partir de 1856 y la última gran oleada de inmigrantes italianos llegaron después de la Segunda Guerra Mundial y en donde los migrantes francófonos llegaron en mayor medida a instancias del desarrollo del ferrocarril a fines del siglo XIX, y cuyas trazas son visibles todavía en manifestaciones culturales y arquitectónicas y en la memoria colectiva ${ }^{5}$, dejar registro de ello se hace cada vez más impostergable. Debido al tiempo transcurrido, gran parte de los inmigrantes italianos han desaparecido y quienes sobreviven tienen una edad superior a los ochenta años. De las migraciones francófonas sólo quedan registros sonoros parciales en la memoria de sus descendientes.

Poder recoger todavía materia sonora de primera mano y recuerdos narrados en la primera y segunda generación es un modo de reconstruir la historia colectiva a través de las experiencias personales. Bibiana Pivetta, investigadora de Rosario con gran experiencia en este tipo de actividades, explica:

La oralidad es un componente relevante del patrimonio cultural inmaterial ya que es la forma que tiene el hombre para relacionarse con sus semejantes, con la naturaleza y de producir y reproducir cultura. La capacidad social para traspasarse de generación en generación va construyendo la memoria colectiva. Así ésta se transforma en un elemento decisivo para la vida comunitaria como lo es la memoria individual para cada uno de nosotros. (Pivetta et al 2009: 76)

En este contexto, durante el 2018 se ha creado una nueva sección llamada Laboratorio de Historia Oral, el cual puede ser visitado en http://www.fhuc.unl.edu.ar/ portalgringo/crear/gringa/LHO/lho.html, dedicado a recoger la memoria sonora de la inmigración a partir del registro de voces y relatos que pueden aportar los inmigrantes que en número ya escaso viven en la ciudad y zona, y sus descendientes.

Con la generación de un espacio virtual destinado a radicar estos documentos sonoros y sus transcripciones, se pretende mantener viva la memoria de todos aquellos que abandonando sus países contribuyeron al desarrollo y el crecimiento de la Pampa Gringa. Con la formalización del laboratorio es posible también incluir registros sonoros y visuales realizados muchos años atrás conservados en cassettes.

El laboratorio es un micrositio que pretende ofrecer al público no solo las entrevistas en formato audio acompañadas por sus debidas transcripciones, sino además fotografías, videos y otros materiales que acompañan las historias narradas oralmente. La propuesta se basa en una serie de entrevistas semiestructuradas mayormente en idioma español donde los informantes son invitados a narrar sus experiencias de vida (partida, llegada, familia, trabajo, estudios, etc.) y se encuentran organizadas en diferentes categorías. 
La primera división tiene que ver con los orígenes de los migrantes: francófonos e italófonos. La sección italófona - que sustenta las intenciones expositivas de este trabajo— ha sido diseńada de la siguiente manera:

- Inmigrantes:

1. Primera generación: comprende a los inmigrantes llegados en edad adulta.

2. Generación 1.5: comprende a los inmigrantes nacidos en Italia pero escolarizados en Argentina.

- Descendientes nacidos en Argentina:

1. Primera generación: Hijos;

2. Segunda generación: Nietos;

3. Tercera generación: Bisnietos.

Estas categorías permiten una descripción meticulosa de cada grupo de pertenencia y posibilita recoger las historias de las primeras familias de inmigrantes arribados a fines de siglo XIX y primeras décadas del siglo XX.

Algunas de estas entrevistas han sido seleccionadas como muestra para los estudios de las lenguas en contacto en la fase inicial del proyecto. Es esta oportunidad presentamos solo algunos resultados recogido en base al análisis de una sola entrevista que sirve como modelo inicial para el análisis a desarrollarse con la muestra completa.

El trabajo colaborativo de los autores del presente trabajo partió de la hipótesis de que el contexto de contacto lingüístico con lenguas de origen ítalo-romance pudo haber modificado de algún modo la lengua española hablada en Santa Fe a nivel lexical, morfológico, fonológico y pragmático.

Partiendo de esta suposición, se diseñó el campo de estudio: el recorrido lingüístico de los inmigrantes italianos en la Pampa Gringa y en particular en la ciudad capital de la provincia. En este contexto, tenemos un interés particular en la detección de posibles innovaciones introducidas en el español regional.

Como se decía anteriormente, seis de las entrevistas que forman parte del Laboratorio de Historia Oral (UNL) Categoría Migrantes de Primera Generación han sido seleccionadas como muestra para los estudios de las lenguas en contacto durante 2019 y fueron elegidas con un criterio geográfico según la proveniencia de los entrevistados:

- dos friulanos (norte)

- dos campanos (centro sur)

- dos sicilianos (sur insular)

Para el desarrollo del análisis se debió elaborar una serie de pautas necesarias para encausar operativamente las actividades compartidas entre los investigadores pertenecientes a dos países geográficamente lejanos como Argentina y Australia, relación en la cual la tecnología de las comunicaciones juega un rol prominente.

Las catorce horas de diferencia en el huso horario entre los dos países es un escollo que se superó con gran voluntad por parte de ambos investigadores y con la ayuda de las nuevas tecnologías que permiten comunicar en forma gratuita en modo de establecer un contacto veloz y eficiente cada vez que se crea conveniente.

Desde el inicio se ha creado una carpeta Dropbox que contiene el material bibliográfico de base, experiencias precedentes, archivos relativos al análisis y documentos electrónicos con los resultados de las investigaciones. 
Las entrevistas están dirigidas generalmente a una persona que tiene el rol de informante pero diseñadas e impostadas pensando en la necesidad de comunicar lo más cómodamente con los entrevistados, ancianos y muchas veces con problemas físicos a causa de la edad ${ }^{6}$.

Luego de realizada la entrevista, es necesaria una transcripción detallada para el análisis sucesivo. El especialista de la sede australiana aportó sus conocimientos y experticia en el diseńo de prácticas para la transcripción.

Como modo de organizar un esquema básico para las mismas, se decidió clasificar mediante colores $^{(*)}$ para reconocer cada intervención más fácilmente:

\begin{tabular}{|l|l|}
\hline ENTREVISTADOR/A: XXX (E) & INFORMANTE: XXX (I) \\
\hline HIJO/A: XXX (H) & NIETO/A: XXX (N) \\
\hline ESPOSO/A: XXX (E) & SOBRINO/A: XXX (S) \\
\hline
\end{tabular}

Acerca de las transcripciones de las categorías Migrantes de Primera Generación y de la Generación 1.5, en la grafía se decidió discriminar el uso lingüístico de los informantes, referencia que se indica en la parte superior izquierda de la primera página de la transcripción. Ejemplo de referencia gráfica:

- Español: Grafía normal y puntuación según parámetros de la RAE;

- Italiano o variante italianizante: utilizada en las locuciones que presentan una impronta típicamente italiana. Se escriben siguiendo las reglas de escritura de la lengua italiana. Grafía cursiva.

- Variante dialectal: solo para las locuciones en las cuales el informante se expresa en lengua materna. Se siguen las reglas de escritura de la lengua italiana. Grafía cursiva negrita.

Presentamos un ejemplo de esta grafía:

E: ¡Ah mire! Claro. Relevaba los datos... ¡Ah, interesante!

I: $\operatorname{De}(s)$ pué(s) mammá portava todo arriba en la municipalidà, todo en la municipalidà.

E: Claro. Así que su familia...

I: No, mammá oh! mammá era! chella tenia che sta' 'ca! Oh, mamma mia! -ríe- Te daba volta arriba-abaco, Santa Fe! Le gustaba metterse adonde había lío, adonde había cosa(s) política(s), esa(s) cosa(s) así y ahí se ponía.

\section{Adaptación de las transcripciones al trabajo de análisis}

La transcripción no es una tarea simple. Además de la necesidad de un sistema coherente, se necesitan también tiempo y paciencia para la ejecución de un trabajo dividido en varios pasos:

\footnotetext{
(*) Nota: en la versión impresa de la revista no se visualizan los colores correspondientes a cada participante de la entrevista.
} 
- Paso 1:

La transcripción de las entrevistas que forman parte de la muestra seleccionada y se presentan en el Laboratorio de Historia Oral tiene una fidelidad al texto oral de un $90 \%$, ya que a veces algunas alocuciones resultan incomprensibles. El primer paso entonces es el de mejorar la fidelidad intentando acercarlo lo más posible al texto original. También se ha procedido a completar las formas inconclusas, insertando entre paréntesis, en particular la «s» en las alocuciones al plural, unidades no pronunciadas por la entrevistada pero que facilita mucho la lectura de la transcripción original.

- Paso 2:

Otro elemento que surgió en la praxis es la competencia limitada del investigador australiano italófono de la variante de español argentino, por lo cual se decidió traducir la entrevista al español en dos versiones. Iniciamos con una versión casi literal que desea reflejar las estructuras del original con alguna inserción de elementos lexicales faltantes en español con el fin de facilitar una comparación directa con el texto original. En este caso, la primera traducción también es acompañada por una serie de explicaciones a fin de simplificar el trabajo. Sucesivamente se ha realizado una segunda traducción al español «limpia», con estructuras frasales normalizadas facilitando la comprensión del texto en su complejidad.

A modo de muestreo y de resolución formal adoptada, presentamos algunos ejemplos de versión mixta original y en una segunda instancia una traducción muy literal a fin de mantener las estructuras originales. La tercera versión contiene la traducción española reordenada:

\section{Ejemplo 1:}

- Versión original:

I: Un capitano que era il Carlo. Vivía al castillo. Po' viviano todo(s) discendiente. Pero era un hombre grande, morió. Despué(s) (e)staban todo(s) discendiente, vivíano n'esse castillo. A Gesualdo. Un castillo así... andava alla plazza e de ahí había una... una subidita, así una escalera como una subidita pero no escalera - escalera así: la calle como una escalera así.

- Versión literal:

I: Un capitán era Carlos. Vivía en el castillo. Luego vivían todos (sus) descendientes. Pero era un hombre grande, murió. Después estaban todos los descendientes. Vivían en ese castillo en Gesualdo. Un castillo así... ibas a la plaza y ahí había una... una subida, así una escalera como una subida pero no escalera - escalera: la calle como una escalera.

- Versión limpia:

I: Carlos era un capitán y vivía en el castillo. Luego vivían todos sus descendientes porque él era un hombre grande y murió. Después residían todos sus descendientes y vivían en el castillo en Gesualdo ${ }^{(* *)}$. Para llegar al castillo había que ir hasta la plaza donde había una rampa, es decir una escalera en forma de rampa que realmente no era una escalera propiamente dicha: la calle funcionaba como una escalera.

\footnotetext{
${ }^{(* *)}$ Nota: se traduce la frase solo como formalidad pero es absolutamente redundante.
} 
Ejemplo 2:

- Versión original:

I: Cerca de la... cerca Avellino, Benevento... toda esa parte de ahí. La zona ${ }^{(* *)}$ esa.

- Versión literal:

I: Cerca de Avellino, Benevento. De esa parte. De la zona ${ }^{(* *)}$ esa.

- Versión limpia:

I: Cerca de Avellino, Benevento. De esa parte. De la zona esa.

Primeras observaciones sobre la entrevista 1. Datos sobre la informante

\begin{tabular}{|l|l|}
\hline Edad & 90 \\
\hline Género & Femenino \\
\hline Ocupación & Ama de casa \\
\hline Región de proveniencia & Campania \\
\hline Fecha de arribo al país & 1951 \\
\hline
\end{tabular}

En general, la forma de hablar de la informante es claramente atribuible al dialecto y a la variedad regional de italiano del centro-sur del país. Se observa que se conserva en modo particular la cadencia típica del habla original debido, tal vez, a la escasa socialización de la señora y a su vida de ama de casa y madre de familia con pocas posibilidades de contacto con nativos aun después de la muerte del marido.

Acerca de las relaciones lingüísticas con el marido, proveniente de la misma zona de Italia, es evidente que una vez en Argentina continuaron usando siempre la lengua madre —el napolitano avelinés — en las comunicaciones intrafamiliares.

Vale la pena también recordar que se trata de una persona escolarizada en Italia donde cursó la escuela media. Cuando habla demuestra un conocimiento medio del italiano regional campano. En Argentina no cursó estudios de lengua española y es evidente que tuvo una autoformación mediante medios de comunicación (radio, tv, etc.) y las poquísimas relaciones sociales que su rol de esposa le permitieron.

Luego del análisis preliminar, podemos notar rápidamente algunos efectos del contacto con el ítalo-romance sobre el español de la entrevistada. Estos ejemplos son ilustrativos y tratan de poner en evidencia algunos efectos del contacto que incluso un análisis preliminar puede relevar:

${ }^{(* * *)}$ Nota: en la transcripción corregida el término es catalogado como italianizante debido esencialmente a la pronunciación $[\mathrm{dz}]$ en vez de $[\Theta]$ característica pronunciación española de España o de [s] pronunciación de la zona central de Argentina. 
- A nivel fonológico:

- «j» con pronunciación fricativa palatal sonora en español se vuelve oclusiva velar [k]. Ej. trabajo: trabaco, bacadita, dico.

- «ll» con pronunciación alveopalatal [J] en español del litoral argentino se transforma en semioclusiva o africada alveopalatal [d]]. Ej. llegamos: gegamo, llegué: geghè, llorar: giorà( $r$ ).

- «Z» con pronunciación de africada [dz], por ej. zona [dzona] y no [sona].

- Caída de la «d» final en sustantivos agudos derivados del latín en dad, por ej. municipalidá.

- Caída de la «r» final de los verbos expresados en infinitivo. Ej. trabajar $>$ trabacà /traßa’ka/.

- A nivel lexical y morfosintáctico:

- Uso del verbo andare en lugar de ir; lavorare por trabajar.

- Cruce lexical, por ej. la plazza = la plaza por la piazza, morió = morì por murió.

- Anteposición del artículo al nombre, fenómeno típico del habla de Santa Fe y que se debe seguramente a un influjo italiano más general, por ej. La Luisa, La Elsa, il Carlo. Ésta no es una característica del italiano meridional pero sí del habla septentrional, como por ejemplo del piamontés, dialecto principal por la masiva inmigración de ese origen en la zona.

- Uso erróneo de las preposiciones, por ej. in casa (a), alla casa (en), sta a Italia (en).

- La ausencia de la -s plural, por ej. discendiente por descendientes.

- Estructura sintáctica dislocada: ¿Qué te parece que ahi viene la Luisa?

- Estructura capicúa: «La Liliana tenía cinque - sei anni, tenía»

\section{Conclusiones}

Las colaboraciones científicas surgen en diferentes modos y pueden también sorprender. En nuestro caso tenemos ya los primeros frutos de un trabajo encarado a dos manos entre investigadores de dos continentes diferentes y muy lejanos desde el punto de vista geográfico, pero ambos interesados en la inmigración italiana y su impacto lingüístico.

Estamos transitando los primeros pasos, unificando y valorando metodologías y técnicas que pueden ser desarrolladas o modificadas ulteriormente, en modo tal que al final se pueda llegar a un análisis exhaustivo del español en contacto con otras lenguas y en particular modo el italo-romance, lo que en sede local permitirá el desarrollo de estudios científicos sobre la incidencia del habla italófona en el español de Santa Fe. 


\section{Notas}

${ }^{1}$ Versión original: «Dall'Italia emigrarono nello scorso anno mezzo milione di abitanti. L'emigrazione nostra, sorta, continuata e aumentata fino a queste spaventose proporzioni in mezzo a troppa indifferenza, è venuta ad un tratto ad imporsi alla nostra preoccupazione come uno dei problemi più gravi, più complessi e più urgenti». La traducción es nuestra ${ }^{2}$ Versión italiana: «Nella lingua è il segreto dell'unione, il baluardo della nazionalità. Ebbene, quanti italiani in Italia parlano italiano?I colti tutti; ma noi sappiamo che disgraziatamente essi non formano la maggioranza nella massa emigratrice. Gli altri parlano ligure, parlano siciliano, romagnolo, lombardo, napoletano, piemontese, ma non italiano. La nostra lingua non va più al nord di Pistoja e più al sud di Roma. Un povero lavoratore abruzzese si troverà di fronte ad un suo compagno d'emigrazione ligure, come di fronte ad uno straniero. [...]». La traducción es nuestra.

${ }^{3}$ Versión italiana: «La lingua "creata" dall'immigrato nel processo di acculturazione ed inserimento linguistico che risulta in un cocoliche o pidgin o "pasticcio" come un "fenomeno d'ibridazione linguistica operato nel parlare degli immigrati e la contaminazione che si produsse tra i loro dialetti o italiano d'origine con lo spagnolo rioplatense». La traducción es nuestra.

${ }^{4}$ Un cuarto tomo de la serie (en prensa, ed. Antonella Cancellier) integra la summa de los trabajos sueltos de Giovanni Meo-Zilio y contiene lo que ha sido publicado, en revistas y obras colectivas, a partir de 1993. ${ }^{5}$ El 30 de noviembre de 2018 y hasta el 1 de marzo de 2019 la Secretaría de Cultura del Gobierno de la ciudad de Santa Fe ha organizado en su Museo «Sor Josefa Díaz y Clucellas» la muestra Migraciones tangibles: herencia francesa y francófona en Santa $F$, bajo la coordinación general de la Prof. Adriana Crolla.

${ }^{6}$ Es muy frecuente la presencia de integrantes de la familia que acompañan y participan de la entrevista.

\section{Referencias bibliográficas}

Barzini, L. (1902). L'Argentina vista comèe. Milán: Tipografia del Corriere della Sera.

Cancellier, A. (2015). «Giovanni Meo Zilio, pionero en los estudios lingüísticos sobre el espacio plural del Río de la Plata». Revista Zibaldone. Estudios Italianos de La Torre del Virrey. III(1). Valencia. Consultado en línea el 15-12-2018 en https://ojs.uv.es/index.php/zibaldone/article/ view/6997.

(2011). El español rioplatense en los estudios dialectológicos de Giovanni Meo Zilio en Di Tullio, A. y Kailuweit, R. (eds.). El español rioplatense: lengua, literatura, expresiones culturales. Madrid-Frankfurt am Main: Iberoamericana Vervuert, pp. 137-152.

Crolla, A. (Comp.) (2015). Italia y Francia en Santa Fe. Diversidades, legados y reconfiguraciones. Santa Fe: Ediciones UNL. 
Djenderedjian, J. (2008). La colonización agricola en Argentina, 1850-1900: problemas y desafios de un complejo proceso de cambio productivo en Santa Fe y Entre Ríos. Am. Lat. Hist. Econ (30), 127-157. [En línea] Consultado 03-02-2018 en http://www.scielo.org.mx/ scielo.php?script=sci_arttext\&pid=S1405-22532008000200004\&ing $=$ es\&nrm=iso.

Di Tullıo, A. (2010). Políticas lingüisticas e inmigración. El caso argentino. Buenos Aires: Eudeba.

Fernandez, J. y Rondina, J. (2004). Historia Argentina - Tomo 1 (1810-1930). Santa Fe: Ediciones UNL.

FERraris, M. (2015). El malón y otros relatos. Buenos Aires: Editorial Dunken.

Giolitto, M. (2016). Palabra de Gringos. El uso del piamontés en la vida cotidiana de los habitantes de la Pampa Gringa. Rosario: Prohistoria Ediciones.

Gschwind, J. (1989). Historia de San Carlos - Tomo 1 (Segunda Edición). Santa Fe, Argentina: Universidad Nacional del Litoral - Fundación Banco Bica.

KRöHLING, R. (2013). Humboldt. Una mirada atrás. Sus primeros cincuenta años. Santa Fe: Acosta Hermanos.

LisI, F. (2004). Interacción del Español y del Italiano en el léxico y la articulación de los inmigrantes italianos y sus descendientes inmediatos en la ciudad de Salta. Salta: CIUNSa.

Meo Zilio, G. (1989). Estudios Hispanoamericanos. Estudios Hispanoamericanos. Temas Lingüisticos, I. Roma: Bulzoni.

(1993). Estudios Hispanoamericanos. Temas Lingüisticos y de Crítica Semántica, II. Roma: Bulzoni.

(1995). Estudios Hispanoamericanos. Temas Literarios y Estilísticos, III. Roma: Bulzoni.

Paso, L. (1985). Raices históricas de la dependencia argentina /2. Buenos Aires: Centro Editor de América Latina.

Pivetta, B, Ballesio, S. y M. Sellares (2009). «Historia oral y migraciones: recursos para activar la memoria colectiva». Espaço Plural. Año X 20, 73-80. Paraná, Brasil: Unioeste.

SAï̀, E. (2004 [1983]). El mundo, el texto y el crítico. [Trad. Ricardo García]. Barcelona: Mondadori.

Williams, R. (2000 [1977]). Marxismo y literatura. [Trad. Pablo di Masso]. Barcelona: Península.

Hajek, John

Dorato, Susana

«La inmigración italiana en Santa Fe: español e italiano en contacto. Motivaciones, metodologías y primeros resultados de un proyecto internacional». El hilo de la fábula. Revista anual del Centro de Estudios Comparados (19), 137-151.

Fecha de recepción: $21 \cdot 02 \cdot 19$

Fecha de aceptación: $09 \cdot 05 \cdot 19$ 